\title{
ENERGIAS RENOVÁVEIS
}

\section{APROVEITAMENTO DOS RESÍDUOS DA TILAPICULTURA PARA PRODUÇÃO DE BIODIESEL: CARACTERIZAÇÃO E AVALIAÇÃO DE MISTURAS COM BIODIESEL DE MAMONA}

Fernando Gonçalves Queiroz (AUTOR PRINCIPAL) - victorbrunodf@ hotmail.com Universidade Federal do Ceará.

Camila Peixoto do Valle (COAUTORA) - camilapvalle@ gmail.com Universidade Federal do Ceará.

Deiby Anne Uchoa Barroso Bizerra (COAUTORA) - deiby_anne@ hotmail.com Universidade Federal do Ceará.

Ranier Alexsander Arruda Moura (COAUTOR) - ranieralexsander@ gmail.com Universidade Federal do Ceará.

Jackson de Queiroz Malveira (COAUTOR) - jackson.malveira@ nutec.ce.gov.br Fundação Núcleo de Tecnologia Industrial do Ceará.

Maria Alexsandra de Sousa Rios (ORIENTADORA) - alexsandrarios@ ufc.br Universidade Federal do Ceará.

Resumo: O aproveitamento de resíduos do beneficiamento da Tilápia se torna opção para a extração de óleo e obtenção de biodiesel no estado do Ceará. Um projeto pioneiro firmado entre a Petrobras Biocombustível e a Secretaria da Agricultura, Pesca e Aquicultura do estado, objetivou a inclusão desta matéria prima no programa cearense de biodiesel. No estado, outra matéria prima para produção de biodiesel é o óleo extraído da cultura da mamoneira (Ricinus communis L.), uma oleaginosa adaptada à característica climática cearense. Quanto às características físico-químicas, o óleo de mamona possui elevada viscosidade, ponto de fluidez e estabilidade oxidativa; enquanto que o óleo das vísceras de Tilápia possui baixa viscosidade, ponto de fluidez e estabilidade oxidativa. Neste sentido, foram formuladas blendas dos biodieseis de óleo de peixe/óleo de mamona, para verificação das características físico-químicas destas, visando adequação aos parâmetros de qualidade adotados pela Agência Nacional do Petróleo, Gás Natural e Biocombustíveis, Resolução ANP $\mathrm{N}^{\mathrm{o}}$ 45, de 25.8.2014. De acordo com os resultados obtidos, as blendas de biodiesel de peixe (BP) e biodiesel de mamona (BM) nas proporções 25/75, 50/50 e 75/25 (BP/BM), apresentaram a melhor estabilidade oxidativa, viscosidade, densidade e poder calorifico.

Palavras-chave: Vísceras de Tilápia, óleo de mamona, blendas e estabilidade oxidativa.

\section{INTRODUÇÃO E OBJETIVOS}



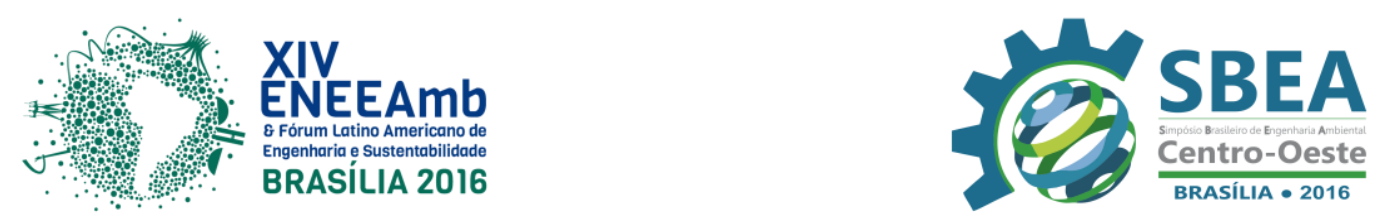

A busca por novas fontes de energia é cada vez mais presente no mundo. Os problemas ambientais têm despertado o interesse sócio governamental para o desenvolvimento de pesquisas que contribuam para a preservação do meio ambiente. Em busca da sustentabilidade, estudiosos utilizam fontes de energia limpa que minimizem impactos ambientais. Os derivados da biomassa são fontes naturais de energia renovável, seu conteúdo, quando em processo de combustão, produz menos poluente que outras fontes energéticas, a exemplo dos combustíveis fósseis. Neste sentido, o reaproveitamento de resíduos da biomassa apresenta-se como opção viável e sustentável.

O óleo extraído da semente de mamona (Ricinus communis L.) desperta interesse em face da oportunidade de desenvolvimento agrícola para as regiões mais áridas. A mamona é facilmente cultivada e bastante resistente à escassez de água, podendo ser alternativa para o desenvolvimento socioeconômico das comunidades agricultoras da Região Nordeste. O óleo extraído desta espécie pode ser utilizado na indústria em diferentes aplicações como: lubrificantes, cosméticos, tintas, plásticos e biodiesel (CANGEMI et al., 2010).

O óleo extraído das vísceras da Tilápia do Nilo (Oreochromis niloticus) é uma matériaprima de origem animal com potencial aplicação na área de biocombustíveis, com rendimento da ordem de $50 \%(\mathrm{~m} / \mathrm{m})$ (SANTOS et al.,2010). A Tilápia é a espécie de peixe que apresenta maior índice de produção na aquicultura nacional (FAO, 2014), sendo o estado do Ceará o maior produtor brasileiro (ADECE, 2013). O açude Castanhão, maior reservatório hídrico do estado (6,3 bilhões de $\mathrm{m}^{3}$ ), gera cerca de 1.800 toneladas/ano, sendo a décima parte desta produção somente de vísceras. O reaproveitamento destes resíduos, que muitas vezes são lançados de forma inadequada no meio ambiente, pode gerar renda as comunidades produtoras do pescado.

Dentro deste cenário, as matérias-primas supracitadas podem ser empregadas na produção de biodiesel, o qual é obtido a partir de lipídios orgânicos, como óleos vegetais e gorduras animais, através do processo de transesterificação. $O$ biodiesel por ser um combustível biodegradável, gerado a partir de fontes renováveis de energia, é praticamente livre de enxofre em sua composição. O enxofre em contato com a atmosfera forma o gás dióxido de enxofre, grande poluente do ar. Quando o dióxido de enxofre se junta à umidade da atmosfera, forma o ácido sulfúrico, um dos principais componentes da chuva ácida.

Este trabalho tem como motivação principal a agregação de valor ao óleo da mamona (Ricinus communis L.) - oleaginosa de conhecido cultivo regional e ao óleo extraído das vísceras da Tilápia (Oreochromis niloticus) - subproduto abundante no estado no Ceará, através da produção de blendas de biodieseis, a partir destes óleos, nas proporções 25/75, 50/50 e 75/25 (BP/BM).

No processo inicial o óleo de peixe foi transesterificado com metanol em meio básico, através do qual foi obtido biodiesel e glicerina. O biodiesel de mamona, também obtido via transesterificação, foi gentilmente cedido pelo Laboratório de Referência em Biocombustíveis Professor Expedito José de Sá Parente (LARBIO), caracterizado e posteriormente, misturado ao biodiesel de peixe para obtenção das blendas nas proporções anteriormente citadas. Os ensaios físico-químicos foram realizados em todas as amostras, permitindo avaliar as 
principais mudanças ocorridas devido à inserção do biodiesel de mamona ao biodiesel de peixe e assim identificar a blenda que apresentara o melhor padrão de qualidade.

\section{METODOLOGIA}

Os procedimentos experimentais utilizados na caracterização das amostras de biodiesel, blendas e óleo das vísceras de Tilápia foram realizados de acordo com os Métodos FísicoQuímicos para Análise de Alimentos do Instituto Adolfo Lutz e normas da ASTM (American Society of Testing and Materials), EN (European Standards), AOCS (American Oil Chemists Society) e da ABNT (Associação Brasileira de Normas Técnicas).

\subsection{Matérias-primas}

O biodiesel de mamona foi gentilmente cedido pelo Laboratório de Referência em Biocombustíveis Professor Expedito José de Sá Parente (LARBIO), o qual estava em estoque desde a primeira quinzena de dezembro de 2014. O biodiesel foi caracterizado e posteriormente misturado ao biodiesel de peixe para obtenção das blendas. O óleo das vísceras de peixe foi obtido a partir do aquecimento direto das vísceras da espécie Tilápia do Nilo (Oreochromis niloticus), coletadas no comércio local de Fortaleza. As blendas de biodiesel de peixe (BP) e biodiesel de mamona (BM) foram preparadas nas proporções $25 / 75$, $50 / 50$ e $75 / 25$ (BP/BM).

\subsection{Tratamento prévio do óleo de vísceras de Tilápia}

O óleo obtido apresentou acidez $(0,21 \mathrm{mgKOH} / \mathrm{g})$ e umidade $(481,5 \mathrm{mg} / \mathrm{kg})$ e foi intitulado óleo bruto. A Figura 1 apresenta o fluxograma com as etapas de refino do óleo extraído das vísceras de Tilápia.

Figura 1 - Fluxograma com as etapas de refino do óleo extraído das vísceras de Tilápia.

\begin{tabular}{|c|}
\hline Óleo bruto \\
\hline Degomagem \\
\hline Neutralização \\
\hline Lavagem \\
\hline Desumidificação \\
\hline Secagem \\
\hline Óleo pré-tatado \\
\hline
\end{tabular}

Fonte: Autores.

\subsection{Produção de biodiesel}

O biodiesel de óleo de peixe foi produzido por rota metílica. O catalisador utilizado foi hidróxido de sódio e a mistura foi submetida a temperatura de $60-70{ }^{\circ} \mathrm{C}$, em sistema sob 

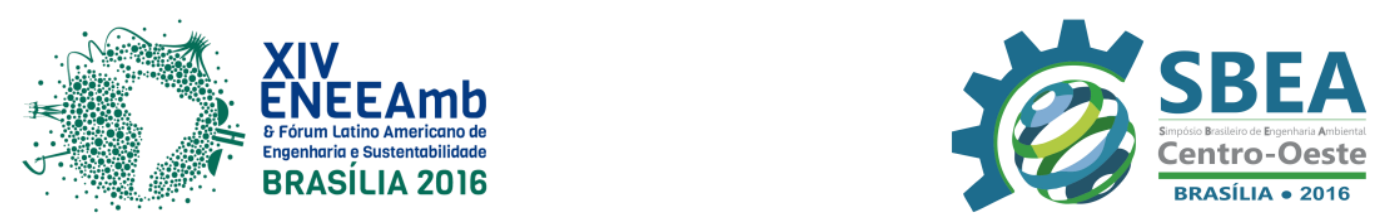

refluxo e agitação constante, por um período de 90 minutos. A solução resultante foi transferida para um funil de separação. Depois de 60 minutos, ocorreu à decantação da glicerina, fase inferior escura e mais densa, sendo a fase éster a fase superior.

A glicerina foi separada e realizou-se o procedimento de lavagem do biodiesel. Foram realizadas três lavagens com água destilada, a $70-80{ }^{\circ} \mathrm{C}$, sendo cada lavagem realizada com $10 \%$ em relação à massa da fase éster. A água para lavagem foi aquecida para remoção de quaisquer resíduos de sabão, catalisador, metanol e/ou glicerina. A secagem foi realizada com sulfato de sódio anidro com o intuito de retirar a umidade remanescente.

\subsection{Caracterizações físico-químicas}

As matérias-primas e o biodiesel de óleo de peixe foram caracterizados por meio da determinação dos parâmetros índice de acidez (ABNT NBR 14448), viscosidade cinemática a $40{ }^{\circ} \mathrm{C}$ (ABNT NBR 10441), massa específica a $20{ }^{\circ} \mathrm{C}$ (ABNT NBR 14065), estabilidade oxidativa (EN 14112), teor de umidade (ASTM D 6304), poder calorífico superior (ASTM D 5865) e ponto de fluidez (ASTM D 97).

\section{RESULTADOS E DISCUSSÃO}

Durante o processo de obtenção e refino do óleo foi observado à formação de duas fases distintas: fase oleosa e fase borra. A fase oleosa corresponde à parte almejada no trabalho, ou seja, o óleo, e a fase borra correspondente a parte indesejável. Na Tabela 1 estão apresentados os resultados das caracterizações físico-químicas. As análises foram realizadas em duplicata.

Tabela 1 - Caracterização físico-química do óleo extraído das vísceras de Tilápia.

\begin{tabular}{c|c|c|c}
\multicolumn{1}{c}{ Ánalises } & Unidades & \multirow{2}{*}{ Metodologia } & Resultados \\
\cline { 4 - 4 } & & & óleo de peixe \\
\hline Índice de acidez & $\mathrm{mgKOH} / \mathrm{g}$ & NBR14448 & $0,21 \pm 0,01$ \\
\hline Viscosidade a $40^{\circ} \mathrm{C}$ & $\mathrm{mm} / \mathrm{s}$ & NBR10441 & $37,15 \pm 0,01$ \\
\hline Massa específica a $20^{\circ} \mathrm{C}$ & $\mathrm{Kg} / \mathrm{m}^{3}$ & NBR14065 & $912,2 \pm 0,01$ \\
\hline Teor de umidade & $\mathrm{mg} / \mathrm{Kg}$ & ASTMD6304 & $481,5 \pm 0,52$ \\
\hline
\end{tabular}

Fonte: Autores.

Com os resultados obtidos é importante verificar que a reação de transesterificação não foi prejudicada, pois para valores de acidez acima $2 \mathrm{mg} \mathrm{KOH} / \mathrm{g}$, o óleo apresenta-se inadequado para produção de biodiesel; e com o teor de umidade acima de $500 \mathrm{mg} / \mathrm{kg}$ a liberação de ácidos graxos livres favorece a formação de sabão. Estes são parâmetros de controle para um bom rendimento do processo de transesterificação (KNOTHE, 2006).

Após o processo de transesterificação foi obtido o biodiesel de óleo de peixe (BP) e em seguida caracterizado, juntamente com o biodiesel de mamona. Os resultados encontram-se descritos na Tabela 2. Os valores expressos são a média das duplicatas. 
Tabela 2 - Caracterização físico-química do biodiesel de mamona (BM) e biodiesel de peixe (BP).

\begin{tabular}{|c|c|c|c|c|}
\hline \multirow{2}{*}{ Ánalises } & \multirow{2}{*}{ Unidades } & \multirow{2}{*}{ Metodologia } & \multicolumn{2}{|c|}{ Resultados } \\
\hline & & & $\mathbf{B M}$ & $\mathbf{B P}$ \\
\hline Índice de acidez & $\mathrm{mgKOH} / \mathrm{g}$ & NBR14448 & 0,47 & 0,44 \\
\hline Viscosidade a $40{ }^{\circ} \mathrm{C}$ & $\mathrm{mm}^{2} / \mathrm{s}$ & NBR10441 & 13,7 & 4,4 \\
\hline Massa específica a $20{ }^{\circ} \mathrm{C}$ & $\mathrm{Kg} / \mathrm{m}^{3}$ & NBR14065 & 917 & 870,2 \\
\hline Teor de umidade & $\mathrm{mg} / \mathrm{Kg}$ & ASTMD6304 & 230,7 & 292,4 \\
\hline Estabilidade Oxidativa & horas & EN14112 & 25,7 & 2,1 \\
\hline Poder Calorífico & $\mathrm{cal} / \mathrm{g}$ & ASTM D5865 & 9044,5 & 9490,5 \\
\hline Ponto de Fluidez & ${ }^{\circ} \mathrm{C}$ & ASTM D97 & -30 & 0 \\
\hline
\end{tabular}

Fonte: Autores.

Em comparação ao óleo, o biodiesel de peixe teve uma grande redução do valor de viscosidade, o que é um indicativo do sucesso da reação de transesterificação. Segundo a literatura (SUAREZ et al., 2007), a alcoólise do triglicerídeo reduz sua massa molecular para $1 / 3$ do valor inicial, como também reduz sua viscosidade. A elevada viscosidade do biodiesel de mamona comparada ao biodiesel de peixe é explicada por um maior número de interações intermoleculares, do tipo ligações de hidrogênio, entre as moléculas do majoritário hidroxilado de ricinoleato de metila.

As blendas foram obtidas através da mistura de biodiesel de peixe e biodiesel de mamona (BP/BM), nas proporções de 25/75, 50/50 e 75/25 (BP/BM). Os resultados das análises encontram-se descritos na Tabela 3.

Tabela 3 - Caracterização físico-química das blendas (BP/BM).

\begin{tabular}{c|c|c|c|c|c}
\multicolumn{2}{c}{ Ánalises } & \multicolumn{1}{c}{ Unidades } & Metodologia & \multicolumn{2}{c}{ Resultados (BP/BM) } \\
Índice de acidez & $\mathrm{mgKOH} / \mathrm{g}$ & NBR14448 & 0,46 & 0,45 & 0,45 \\
\hline Viscosidade a $40{ }^{\circ} \mathrm{C}$ & $\mathrm{mm}^{2} / \mathrm{s}$ & NBR10441 & 8,7 & 6,0 & 5,0 \\
\hline Massa específica a $20^{\circ} \mathrm{C}$ & $\mathrm{Kg} / \mathrm{m}^{3}$ & NBR14065 & 898,4 & 884,1 & 872,6 \\
\hline Teor de umidade & $\mathrm{mg} / \mathrm{Kg}$ & ASTMD6304 & 315,1 & 325,1 & 349,1 \\
\hline Estabilidade Oxidativa & horas & EN14112 & 20,9 & 14,1 & 7,4 \\
\hline Poder Calorífico & cal/g & ASTM D5865 & 9075,5 & 9160,0 & 9369,0 \\
\hline Ponto de Fluidez & ${ }^{\circ} \mathrm{C}$ & ASTM D97 & -8 & -2 & 5 \\
\hline
\end{tabular}

Fonte: Autores. 

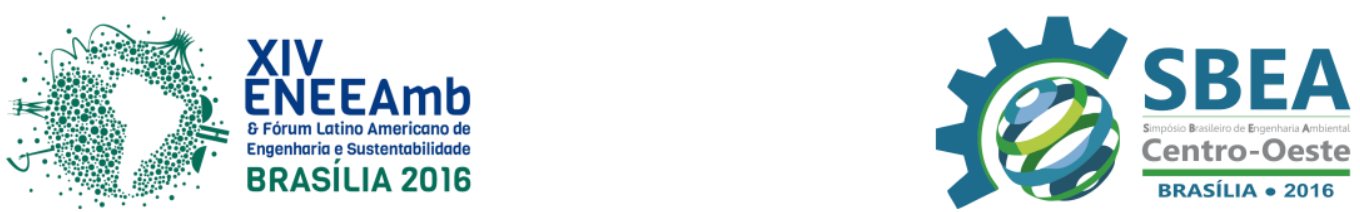

Os resultados do índice de acidez não apresentaram alteração significativa após a formação das blendas. Os resultados de teor de água mostraram que as blendas sofreram absorção de umidade. Um resultado importante foi o de estabilidade oxidativa para as blendas 25/75 e 50/50 (BP/BM), o qual obteve valores superiores ao tempo de estabilidade requerido (8 horas) na Resolução ANP 45/2014, mesmo na ausência de aditivos antioxidantes.

Como observado na Tabela 3, a estabilidade oxidativa das amostras de biodiesel de peixe (BP) e da blenda BP/BM (75/25) não apresentaram resultados em conformidade com o valor estabelecido pela ANP. Para estas amostras, o inconveniente poderia ser sanado com o auxílio de antioxidantes sintéticos e/ou naturais, que ao serem acrescidos ao biocombustível, conferem maior estabilidade e resistência à oxidação (DIAS, 2009). As outras amostras apresentaram valores em conformidade com o padrão de qualidade adotado.

Quanto ao poder calorífico, o mesmo afeta o estado, o desempenho e a eficiência de um motor. O poder calorífico está também relacionado ao consumo, pois quando maior é o poder calorífico menor é o consumo. Os biodieseis e suas blendas apresentaram energia inferior quando comparados ao poder calorífico do diesel (10100 cal/g), ver Figura 2.

Figura 2 - Poder calorífico dos biodieseis e de suas blendas.

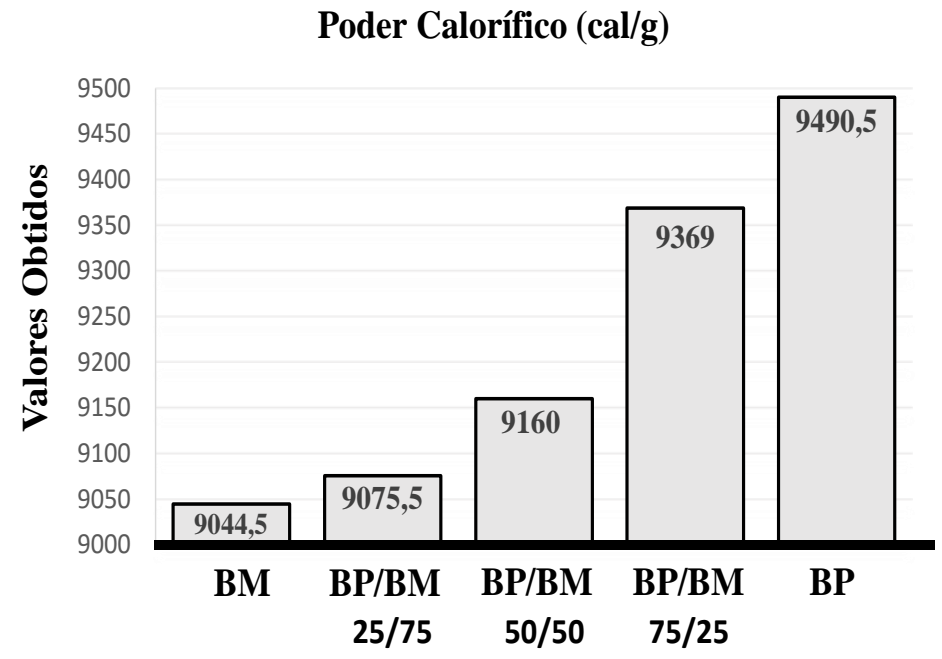

Fonte: Autores.

\section{CONSIDERAÇÕES FINAIS}

De acordo com os resultados obtidos, pode-se concluir que o óleo extraído das vísceras de Tilápia pode ser utilizado como matéria-prima na produção de biodiesel, assim como, na produção de blendas de biodiesel de óleo de peixe/biodiesel de óleo de mamona. A utilização do óleo das vísceras de Tilápia na produção de biodiesel pode reduzir os impactos ambientais, decorrentes da indevida destinação dos resíduos sólidos da Tilapicultura (vísceras). O biodiesel derivado do óleo de mamona, devido à composição química singular de seus ácidos graxos, apresentou bons resultados físicos e químicos, tais como: estabilidade oxidativa e ponto de fluidez. Os valores do ponto de fluidez para o biodiesel de mamona, a temperaturas negativas, sugerem o uso deste biodiesel em países de clima frio. 

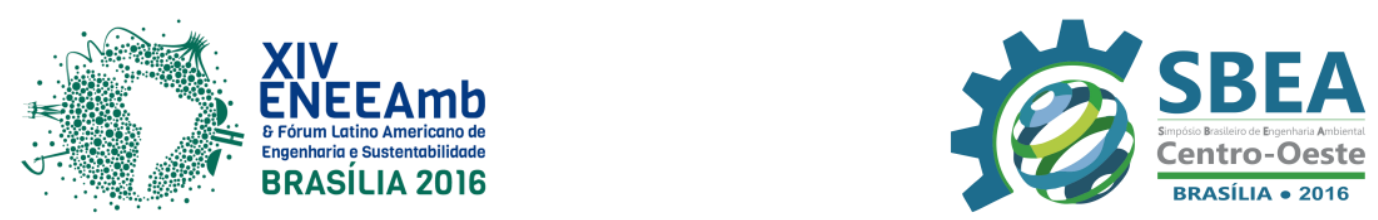

O acréscimo do biodiesel de mamona ao biodiesel de peixe melhorou significativamente a estabilidade à oxidação da blenda, assim como, o biodiesel de peixe proporciona a redução da viscosidade cinemática da blenda, proporcionando melhor atomização em câmaras de combustão. Considerando as propriedades dos fluidos foi observado que à medida que aumenta o teor de biodiesel de mamona (BM) ao biodiesel de peixe (BP), ocorre um decaimento do ponto de fluidez, sugerindo que a adição de biodiesel de mamona tende a melhorar as propriedades de fluxo a frio do biodiesel de peixe agindo como um possível componente anti-congelante.

Os resultados comprovaram que, a blenda biodiesel de peixe e biodiesel de mamona, na proporção 50/50, apresentou os melhores resultados, corroborando com os limites aceitáveis na Resolução ANP Nº 45/2014.

\section{REFERÊNCIAS E CITAÇÕES.}

CANGEMI, J. M., A. M. d. Santos, et al. (2010) A Revolução Verde da Mamona. Química Nova v.32, 6p.

SANTOS, F. F. P., J. Q. Malveira, et al. (2010). "Production of biodiesel by ultrasound assisted esterification of Oreochromis niloticus oil." Fuel 89(2): 275-279.

FAO (2014). "Fishery and Aquaculture Statistics: The Federative Republic of Brazil.". http://www.fao.org/fishery/facp/BRA/en. acessado em: 18 de maio de 2015.

ADECE (2013). Agronegócio Cearense, Retrieved 15 Nov. 2013, Disponível em: http: //www.pecnordestefaec.org.br/2013/content/uploads/2013/09/PRATICAAGRONEGOCIO.pd f. Acesso em 13 de junho de 2015.

KNOTHE, G., J. V. Gerpen, et al. (2006). Manual de Biodiesel. São Paulo, Editora Blucher: $352 \mathrm{p}$.

SUAREZ, P. A.Z. et al. Transformação de triglicerídeos em combustíveis, materiais poliméricos e insumos Químicos: algumas aplicações da catálise na oleoquímica. Quim. Nova, Vol. 30, No. 3, 667-676, 2007.

DIAS, F. P. (2009). Aproveitamento das Vísceras de Tilápia para Produção de Biodiesel. Departamento de Engenharia Hidráulica e Ambiental. Fortaleza- CE, Universidade Federal do Ceará. Mestrado: 106 p.

AGÊNCIA NACIONAL DO PETRÓLEO - ANP. Resolução ANP 45 de 25/08/2014.Disponivel em: http://www.anp.gov.br. Acesso em 13 de maio de 2015.

AMERICAN SOCIETY FOR TESTING AND MATERIALS (ASTM). Method D6304: Standard Test Method for, Determination of water in petroleum products, lubricating oils, and additives by coulometric Karl Fischer titration. 2009. 